\title{
The Use of Neuroleptanaesthesia for Experimental Orthopaedic Surgery in the Rabbit
}

The anaesthesia of the rabbit used as a laboratory animal in experimental orthopaedics may present problems. The anaesthetic method should be easy and safe. Preferably it should not be expensive and should not include sophisticated devices. The anaesthesia has to include all the components: complete analgesia, muscular relaxation, and sedation. The application of the anaesthesia should not cause anxiety and pain to the animal, e.g. rigorous restraint has to be avoided.

Several anaesthetic techniques for use in rabbits are described in the literature (Green 1979). Induction, intubation and maintenance of the anaesthesia with a volatile anaesthetic agent is a safe method, but it may be rather complex and time-consuming in practice (Alexander \& Clark 1980, Zahavi et al. 1983). Pentobarbital sodium is sometimes used as an intravenous injection, but the therapeutic index of this agent is narrow. Ketamine combined with xylazine has been reported to produce a good anaesthesia, but the mortality rate seems to be high (White \& Holmes 1976, Green 1979). A combination of fentanyl and fluanisone produces satisfactory sedation and analgesia, but muscular relaxation is poor (Green 1979).

It has been suggested that by combining diazepam with fentanyl and fluanisone very satisfactory surgical anaesthesia can be achieved (Flecknell et al. 1983). The present study describes the use of that combination in the anaesthesia of the rabbit when developing new methods for the fixation of frac- tures. The authors have developed biodegradable implants for the fixation of fractures (Biofix ${ }^{\mathrm{TN}}$ ). These methods have been tested on rabbits. Rabbits of 5 weeks of age were used for operations of epiphyseal plate, and adult animals served as objects for the fixation of osteotomies of mature bone. 224 adult rabbits were operated by performing osteotomies of the distal femur or tibial shaft. An epiphyseolysis of the distal femur was performed on growing rabbits and fixed with biodegradable implants or Kirschner wires or only a drill hole was made through the epiphyseal cartilage. A total of 565 rabbits were operated on one leg.

Atropine was given $1 \mathrm{mg} / \mathrm{kg} 1 / 2 \mathrm{~h}$ before the anaesthesia which was induced by injecting $0.3 \mathrm{ml} / \mathrm{kg}$ fentanyl-fuanisone combination $\left(\right.$ Hypnorm $^{R}$ ) and diazepam $5 \mathrm{mg} / \mathrm{kg}$ (Diapam $^{R}$ ). Procaine penicillin (Procapen ${ }^{R}$ ) was administered 50,000 IU/kg simultaneously to prevent postoperative infections. All the drugs were injected subcutaneously. The stage of surgical anaesthesia was considered to be reached, when the animal was unconscious, did not react to shaving of the operative field, and when the pedal withdrawal and ear pinching reflexes were absent. If the surgery could be performed without any reactions of the animal, the anaesthetic method was considered successful. At the end of the operation $0.1 \mathrm{mg} / \mathrm{kg}$ of naloxone (Nalonee ${ }^{R}$ ) was injected intramuscularly. In case of respiratory distress during operation naloxone was administered intravenously into the auricular vein, and the animal was 
ventilated with a mask until it began to breath normally.

Fentanyl, fluanisone and diazepam in combination resulted in an excellent surgical anaesthesia for orthopaedic operations lasting $30-45 \mathrm{~min}$. The induction time varied from 15 to $30 \mathrm{~min}$ in adult and from 3 to 12 min in growing animals. Sedation, analgesia, an relaxation were satisfactory. The mortality during the anaesthesia was $1.4 \%$ $(8 / 565)$. Resuscitation with artificial ventilation and naloxone was succesful in 5 cases. When naloxone was injected at the end of operation, the rabbits reacted after 2-3 min but were still quite sedated and not able to walk due to the effect of diazepam and fluanisone. Postoperative infections occurred in 6 cases.

The present results in 565 rabbits confirm the findings of a previous study, in which a surgical anaesthesia was induced in 30 adult rabbits (Flecknell et al. 1983). We prefer to administrate all the drugs subcutaneously, because the absorption of the agents will then occur more slowly and evenly and the concentration peaks resulting in respiratory depression might be less probable than when giving the drugs intravenously, intramuscularly or intraperitoneally. Atropine should be given as a premedication, because Hypnorm $^{R}$ may cause severe bradycardia due to vagal stimulation.

The anaesthetic method can be well applied without assistance. The safety of the anaesthesia is high, the mortality rate being $1.4 \%$. This is partly due to an effective anti- dote for fentanyl, in this case naloxone. Postoperative analgesia was maintained by fluanisone because the animals used their operated limb freely. Procaine penicillin was injected simultaneously with anaesthetics to achieve tissue concentration before starting the surgery. It prevented postoperative infections effectively, the infection rate being only $1.1 \%$. No side-effects, e.g. diarrhea or superinfections, were observed.

In conclusion, fentanyl, fluanisone and diazepam used in combination are well suited for anaesthesia in the experimental orthopaedic surgery in rabbits.

\section{Mero, A. Mäkelä, S. Vainionpää, K. Vihtonen \& P. Rokkanen, \\ Department of Surgery, \\ College of Veterinary Medicine, Finland.}

\section{Reference}

Alexander DJ, Clark GC: A simple method of endotracheal intubation in rabbits (Oryctolagus cuniculus). Lab. Anim. Sci. 1980, 30, 871 -873 .

Flecknell PA, Mitchell JM, Shurey C, Simpkins S: Neuroleptanalgesia in the rabbit. Lab. Anim. 1983, 17, 104-109.

Green CJ: Animal Anesthesia. London Animal Ltd. pp 131-138 (1979).

White Fl Holmes DD: A comparison of ketamine and the ketamine xylazine combination for effective surgical anaesthesia in the rabbit. Lab. Anim. Sci. 1976, 26, 804-806.

Zahavi J, Shaffer EA, Sturin L, Gall DG: A simple and safe method of anaesthetizing infant rabbits for abdominal surgery. J. Surg. Res. 1983, 24, 94-95.

(Received April 6, 1987).

Reprints may be requested from: Matti Mero, Department of Surgery, College of Veterinary Medicine, Hämeentie 57, SF-00550 Helsinki, Finland. 